Témoigner Témoigner. Entre histoire et mémoire

Getuigen Revue pluridisciplinaire de la Fondation Auschwitz

$123 \mid 2016$

Traduire le témoignage

\title{
Bridge of Spies: Helden in de schaduw
}

Bridge of spies / Le pont des espions: Héros de l'ombre

\section{Erik Machielsen}

Traducteur : Anneleen Spiessens

\section{(2) OpenEdition}

\section{Journals}

Édition électronique

URL : https://journals.openedition.org/temoigner/5055

DOI : 10.4000/temoigner.5055

ISSN : 2506-6390

Éditeur :

Éditions du Centre d'études et de documentation Mémoire d'Auschwitz, Éditions Kimé

Édition imprimée

Date de publication : 1 octobre 2016

Pagination : 9-12

ISBN : 987 2-9600926-4-6

ISSN : 2037-4183

Référence électronique

Erik Machielsen, «Bridge of Spies: Helden in de schaduw», Témoigner. Entre histoire et mémoire [Online], 123 | 2016, Online op 02 novembre 2021, geraadpleegd op 04 novembre 2021. URL: http:// journals.openedition.org/temoigner/5055; DOI: https://doi.org/10.4000/temoigner.5055

Tous droits réservés 


\section{BRIDGE OF SPIES \\ HELDEN IN DE SCHADUW}

FILM Werkelijk, nóg een film over de Koude Oorlog? Dat liedje kennen we ondertussen. Of toch niet? De namen van Steven Spielberg en Tom Hanks in de aftiteling prikkelen in ieder geval onze nieuwsgierigheid.
Met achtentwintig films op zijn conto heeft Spielberg nog niets aan jeugdigheid ingeboet. Uit Bridge of Spies blijkt meer dan ooit zijn voorliefde voor helden in de schaduw, gewone mannen of vrouwen die worden gedreven door integriteit en eergevoel.

\section{EEN GEWONE KEREL}

Als we dan toch de vergelijking maken: zijn Schindler is dit keer James Britt Donovan, een gewone Amerikaan, trouwe echtgenoot en liefhebbende vader, die een rustig leventje leidt als goede burger. Een onopvallende, ongedwongen kerel die opgaat in de massa. Een discreet man die later gevaarlijk efficiënt zal blijken.

Zonder hem zou de wereld er ongetwijfeld anders hebben uitgezien. Wie de vroege jaren zestig van Kennedy en Chroesjtsjov nog heeft meegemaakt, herinnert zich misschien de figuurvan Donovan. Televisie en kranten brachten toen uitgebreid verslag uit van een gebeurtenis die een heuse wereldoorlog had kunnen ontketenen tussen de twee grootmachten van die tijd.

\section{ABEL OF FISHER?}

We bevinden ons midden in de wapenwedloop tussen de Verenigde Staten en de Sovjet-Unie. Elk blok beschikt over atoomwapens en volgt met arendsogen de vooruitgang en technieken van de ander om niet achterop te hinken. Uiteraard spelen de geheime diensten een essentiële rol in dit verhaal. Aan Rus-

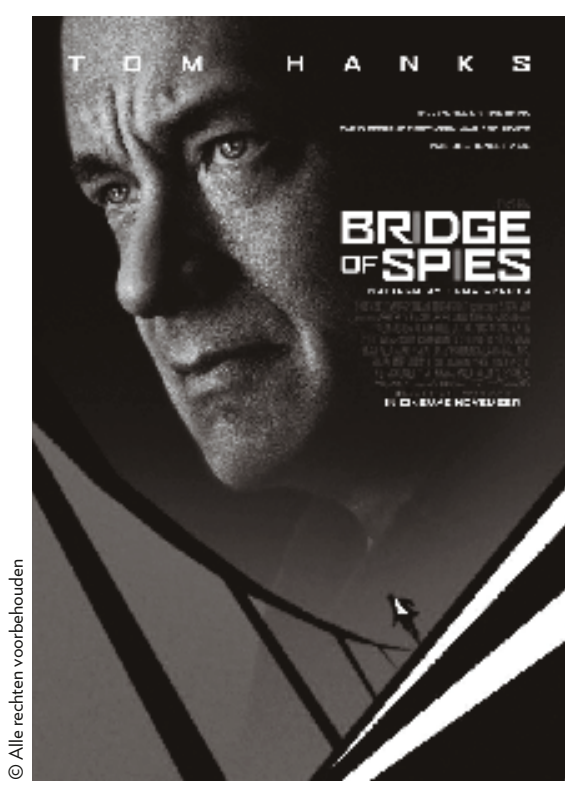

sische zijde vinden we William Fischer. Een van de aliassen waaronder hij werkt is Rudolf Abel, de naam die later ook wordt gebruikt tijdens zijn proces. Spielberg veroorlooft zich een aantal zijsporen en inkortingen - de film is tenslotte 'gebaseerd' op historische feiten - en kiest ervoor om alleen de naam Abel te gebruiken.

Eind 1948 omzeilt Fischer/ Abel de immigratiedienst en bereikt de VS via Canada. Zijn missie? Inlichtingen inwinnen over het nucleaire programma van de VS en een radioverbinding opzetten met Moskou. Hij vestigt zich in Brooklyn, waar hij de identiteit van een overleden Amerikaan aanneemt: Emil Goldfus. Zijn dekmantel: kunstschilder.

\section{Al...}

Enkele jaren later stuurt de CIA zes U-2-verkenningsvliegtuigen naar de Sovjet-Unie om het gebied van bovenaf te filmen. Daarbij schenden ze het Russische luchtruim. Een van de vliegtuigen wordt neergehaald, maar de piloot, Francis Gary Powers, ontkomt met zijn parachute. Bij zijn landing wacht een ontvangstcomité hem op. Bestemming: de gevangenis ••• 
œ van Vladmir. Aanklacht: spionage. D CIA heeft meteen een groot probleen want Powers slikt zijn cyanidepil niet onthule tijdente Zijn gebrek aan loyateit wogingen. zijn gebrikk an loyaur wijkt hit film.

De Rus in de VS, de Amerikaa in de Sovjet-Unie. Op een dag zullen dwee mannen mekaar kruisen in Diverijn op det Potsdam verbindt. Hori Wel, datis precies hetver van Bridge of Spies.

BRIDGE OF SPIES, SCÈNE 1, ACTIE!

1957: een lieflijk en onschuldig tafereel. Een man an middelbare leeftijd werkt in opperste concentratie aan een schilderij van de Brooklyn Bridge. Enkele mannen volgen hem, het zijn agenten van de FBI. Z laten de man zijn huis binnengaan, wachten even af breken dan binnen in zijn kleine appartement. De ma staat in zijn ondergoed in de badkamer. Hij biedt geen weerwerk, legt zich bij zijn lot neer, zegt amper een woord en volgt de agenten gewillig. Het begin van de film.

De man, Rudolf Abel, blijft verbazingwekken alm en beleefd. Hij begrijpt de verdachtmakingen niet en weigert samen te werken met de FBI in ruil voor informatie en zijn vrijlating. Het draait dus uit op een proces. En aangezien er in Amerika niet word leling van de Ronage (her), lijkt de elektrische sto deling van de Rosenter nontkoombaar.

Om niet te worden betrapt op fouten, gebruiken de Amerikanen niet de stalinistische methodes die ze bij hun vijand hekelen, maar doen ze alles volgens het boekje - toch watdevombetreft. Dehulpvan James Donovan wordtingeroepen, een verzekeringsadvocaa ile tijderi de oorlog samente ma lolbijkt dat Donovan zich heeft voorgenomen het grondwettelijk recht naar de letter te volgen, ook al cliënt cliënt van de doodstraf te redden.

WOULD IT HELP ?

Donovan ontmoet Abel en het klikt tussen de twee. Wat hen verbindt, is niet medeplichtigheid in de mis-

daad, maar wederzijds respect. Donovan is onder de indruk van Abels kalmte in het aangezicht van een schijnbaar onvermijdelijke dood en vraagt hem of ij dan geen angst heeft. Abel antwoordt: 'Would it help?' Dat zinnetje horen we meermaals in de film en Omdat hij een Ruldere geest en gezond verstand. Omdat hij een Russische spion verdedigt, word Donovan vereenzelvigd met zijn cliënt en als antipatriot gebrandmerkt. Het Amerikaanse volk, geconditoneerd door het stompzinnige instantdenken van de media, kiest resoluut voor de ontkenning. Niemand distert naar de argumenten van Donovan die de misde leggen: Abel s niet tegen Amerika, hij is vóor de Sovjet-Unie. Die nuance, zo hoopt hij, zal ervoor zorgen dat zijn cliën

Zoals te verwachten viel, wordt Abel tijdens zijn proces echter op alle punten schuldig bevonden doo de volksjury. Aan de rechter komt het nu toe om het verdict te vertalen in een straf. Donovan gelooft dat de rechter ervan te overtuigen dat Abel levend mee de rechter ervan te overtuigen dat Abel levend mee waard is dan dood. De toekomst zal hem gelijk geven. Met tegenzin, maar overtuigd door Donovans pleidooi, Ondert de rechter Abet tot dertigjaar opsluiting om koers te zetten richting Sovjet-Unie. vliestuigen zordt uit de lucht Gary Powers, veroorde voor zijnver zijn verheugd over de gevangenneming van Powers en, waarschijnlijk om dezelfde reden als de Amerikanen (nou verje uit ve stellen ze voor on de spion netwerk wisselen. Voor deze geheime operatie wordt Donovan opnieuw benaderd. Hij aanvaardt de opdracht, vertelt zijn vrouw dat hij op zalm gaat vissen in Engeland, en trekt naar Berlijn, goed wetende dat hij geen enkele diplomatische bescherming geniet als de opdracht fout loopt.

SPANNING EN SENSATIE.

Het eerste deel van de film gaat over de strijd van Donovan om zijn cliënt van de doodstraf te redden in . Het tweede deel speelt zich af in Berlijn. We volgen de advocaat die onderhandelt over de uitwisseling tussen Powers en Abel. Op een bepaald moment, en op de vrijlating te eisen van de Amerikant de vrijlating te eisenvande Anon deric rie de De CIA is niet opgezet met die plotse ingeZifs vor on be bijzonder spannend tot op het eind. de twee kampe staan oog in oog met elkaar op de brug. Ze wachten he signaal af waarop de beidegevangenen naar voren stappen, hun challenger bidisen en ell hun eigen kamp worden opgenom. Dat signal is Frederic Pryor, Che Checkpoint Charlie, de grenspost tussen de Russisch en Amerikaanse sector in de Bellinse muur.

In de film geraakt de student niet tijdig in het Westen, want de laatste steen wordt in de muur geplaats precies op het moment dat hij wil oversteken. Omdat hij Amerkaan is, kan hetenvelin principe snelverholpen worden, maar hij heeft een fotocamera en een map bijzich meteen studiewerkover het communisme. Vodoende on te worden verbich Wlaatste te wo wen aangehouden

Wanneer Donovan dit nieuws te horen krijgt, probeert hijhet gegeven in de onderhandelingen te betre ken. Het probleem is dat Pryor onder de autoriteit van ort-Duitsland valt, dat graag als volwaardige partner Dordt beschouwd en niet als hulpje van de Sovjets. Donovan moet de Oost-Duitsers dus op hun verantwoordeljkheid wijzen: als ze weigeren on Pryor vij te laten, blijft Abel in Amerika. De Sovjets zullen he dan op het matje roepen.

Het verhaal van de uitwisseling, een thriller van John le Carré waardig, zou in 1965 verfilmd worden op initiatief van Gregory Peck. Peck wilde zelf in de hui van Abel. Maar de Koun en zag Alec Guinness in de rol net opsellen van Russische raketten in Caba De ketten in Cuba. De panning was opnieuw opgelopen en de tijd was no niet rijp voor een verfilming.

PARENTHESE

Nu we het over Cuba hebben: na zijn succes in Berlijn kreeg Donovan van president Kennedy de opdracht om de vrijlating en terugkeer te onderhandelen van 1113 Cubaanse ballingen die door de CIA waren opgeleid om het regime van Fidel Castro omver te werpen. U herinnert zich ongetwijfeld de invasie in de Varensbaai, door deze ballingen, in april 1961. Donovan ntmoette de Líder Máximo verschillende keren en, net als bij Abel en ondanks hun verschillende opvattingen, ontwikkelde zich een onderlinge verstandhouding. Ze konden het zo goed vinden dat ze samen gingen vissen, en Donovan Castro een horloge cadea deed dat de Cubaanse leider dagelijks ging dragen. OP culija over de vrijlating van de 1113 gevangenen in ruil voo volu voed. Det ende van de waarbij Donovan 9703 mannen, vrouwen en kinderen ist te bevrijden

Om maar te zeggen, en daarmee de parenthese te tie niet mat sinds 1965 hetgehen tie niet meer zo belangrijk is. Het is dan ook nergen voor nodig om vandaag de dag een verhaal over Amehijvoninver syrie bepaalde spanninge weer doet oplaaien.

VAN CHARMAN TOT SPIELBERG

Het is Matt Charman, een dertigjarige Engelse scenarist, die aan de basis ligt van Bridge of Spies. Tijdens het lezen van een Kennedybiografie (An Unfinisved Life. John Fennedy, 1917-1963van Robert Dallek viel hem in het Cuba-hoofdstukeen voetnootop waarin wot Cancerat die met Castro had onderhandeld, ook verantwoordelijk was voor de vrijlating van Gary Powers. Charman had oor de anonimiteit van zo, door de anonimiteit van zo'n cruciale figuur. Hij ging en nav cont op met de familie ven en nan contact op met de fanilie van Donovan. De samenvatting van zijn onderzoek stuurde hij naa Amblin, Steven Spielbergs bedrijf. Tot zijn verbazing nog groter toen Spielber zelf hem opbelde om hem og groter toen Spielberg zelf hem opbelde om hem te 
•• vragen een scenario uit te werken. De regisseur was zo enthousiast dat hij bereid was de productie in zijn drukke agenda in te passen.

\section{COEN BROTHERS TO THE RESCUE}

Dat de film ondanks het complexe verhaal toch overzichtelijk is gebleven, hebben we te danken aan de vlotte en bondige schrijfstijl van de gebroeders Coen (die ook al tekenden voor The Big Lebowski). Zij namen het eerste scenario van Charman onder handen, maakten het levendiger en minder feitelijk, en legden er een tempo in dat het ritme van Spielberg, hier trager dan gewoonlijk, moest compenseren. Geen woord te veel, elke zin is belangrijk. De Coen-broers namen zelf contact op met Spielberg, eerder uitvoerend producer van hun remake van True Grit, toen ze lucht kregen van zijn plannen. In Bridge of Spies leggen de Coens de nadruk op het absurde van bepaalde situaties. Met een vleugje humor nemen ze de dramatische piek weg uit een aantal scènes die zich afspelen op het scherp van de snee. Zo creëren ze een bepaalde afstand zonder het verhaal banaal te maken. Het scenario is nergens gejaagd, maar steeds gecontroleerd en beheerst, naar het voorbeeld van Donovan die zich sereen voortbeweegt over de hete kolen onder zijn voeten.

Geen enkele van de 142 minuten die de film telt, verveelt. Buiten de scène waarin het vliegtuig van Powers wordt neergeschoten, is het niet het spektakel dat beklijft, maar het beeldverhaal: een aangeboren talent van Spielberg dat altijd zijn sterke punt is geweest en van hem een groot cineast maakt in de rangorde van Capra, Hitchcock, Truffaut of Lean.

Een paar probleempjes doken echter op bij de release van de film. Giles Whitell, voormalig correspondent van de Times in Moskou, eiste de rechten op voor de titel, die hij in 2010 al koos voor zijn boek over hetzelfde onderwerp (de uitwisseling van gevangenen tijdens de Koude Oorlog). Maar waar Spielberg zijn verhaal gedeeltelijk baseert op het boek van James B. Donovan zelf, Strangers on a Bridge uit 1964, en de advocaat als hoofdpersonage neemt, volgen we in het boek van Whittell voornamelijk de gevangenen.

\section{DE CAST}

Tom Hanks is de James Stewart van onze tijd, de sympathieke buurman. Niemand is geschikter voor de rol van James Donovan. Hanks mag dan niet de looks hebben van een Brad Pitt of het charisma van een Daniel Day Lewis, met zijn innemende persoonlijk- heid en menselijkheid weet hij de kijker te overtuigen om zijn kant te kiezen en mee te gaan in zijn logica. Bovendien lijkt de acteur vrij sterk op het historische personage. De echte Donovan had alleen wat minder haar.

De grote verrassing van de film is wel Mark Rylance: wat een revelatie! Een volslagen onbekende voor het grote publiek, maar hij is gewoonweg Rudolf Abel. Op een impressionante manier en met een ijzingwekkende kalmte geeft hij gestalte aan de eenvoud van het personage: een subtiele beweging van zijn wenkbrauw, een indringende blik, de monotonie in zijn stem. Dat verdient een Oscar, en die stak Rylance dan ook met veel gemak op zak. Daarnaast is Alan Alda ons bijgebleven in de rol van Thomas Watters Jr, partner in Donovans advocatenbureau. Alda kende zijn fifteen minutes offame in de jaren zeventig met de televisieserie $M^{*} A^{*} S^{*} H$.

In de coulissen laat de trouwe Janusz Kaminski zich opnieuw opmerken door zijn typerende stijl: onderbelichting, clair-obscur, weinig gesatureerde kleuren, allemaal kenmerkend voor Spielbergs films (buiten de computeranimatie van Tintin) sinds 1993, het jaar waarin Kaminski director of photography werd van Schindler's List. John Williams stond deze keer niet in voor de muziek door gezondheidsproblemen. Thomas Newman (neef van Randy) verzorgde de soundtrack, en deed dat op meer dan verdienstelijke wijze.

Wat is nu het doelpubliek van de film? Voor de 'rapgeneratie' is de Berlijnse muur immers geen referentiepunt meer. Of het nu gaat om de Muur, de Franse Revolutie of de Eerste Wereldoorlog: dat valt voor hen allemaal onder de noemer 'geschiedenisles'. De jeugd was in de periode van de Muur nog niet geboren en heeft die gebeurtenis dus niet bewust beleefd. Dankzij het genie van Spielberg, dat de tijdvakken overstijgt, krijgt ze hopelijk toch zin om de film te gaan bekijken. En telkens opnieuw te bekijken.

Erik Machielsen Vertaling: Anneleen Spiessens 